Research Article

\title{
The Icarus Effect Rephrased: Range of Semantic Gravity and Forms of Knowledge in New Norwegian Teacher Education
}

\author{
Erik Bratland (i) and Mohamed El Ghami \\ Faculty of Education and Arts, Nord University, 8700 Nesna, Norway \\ Correspondence should be addressed to Mohamed El Ghami; mohamed.el-ghami@nord.no
}

Received 29 March 2021; Revised 28 June 2021; Accepted 17 July 2021; Published 24 July 2021

Academic Editor: Eddie Denessen

Copyright (c) 2021 Erik Bratland and Mohamed El Ghami. This is an open access article distributed under the Creative Commons Attribution License, which permits unrestricted use, distribution, and reproduction in any medium, provided the original work is properly cited.

\begin{abstract}
In the 2000s, several major education reforms have been implemented in Norway. The reform in the teacher education is heavily inspired by the Finnish model, with introduction of a new research-based content, with the aim of developing a new type of professional knowledge, as a basis for teachers' professional practice. Drawing on Maton's Legitimation Code Theory, this paper explores the tensions in the new Norwegian teacher education, between knowledge and ways of knowing, by examining students' practices, expressed in students' research and development papers in the new teacher education. The paper refutes a one-dimensional concept of experience-based practical knowledge in the teacher education and argues that professional knowledge is based on practices that are informed by specialized and theoretical knowledge.
\end{abstract}

\section{Introduction}

The school and teacher education in Norway and the Nordic countries have for a long time been characterized by a special type of reform pedagogy. This pedagogy, also referred to as progressive pedagogy, has major implications for the organization of the learning processes and for the perception of knowledge in education [1-3]. The reform pedagogy's ideas about learning and knowledge can be characterized as reflecting what Maton called a "subjectivist doxa" [4], which finds decisive inspiration in various learning theories, not least constructivism, and where knowledge is basically understood as mental processes "in the head of persons" (see [5] (pp. 1)). In recent decades, the hegemony of the progressive pedagogy in schools and teacher education has been strongly challenged $[6,7]$, which is particularly associated with the introduction of international large-scale surveys in Norwegian schools: Programme for International Student Assessment (PISA), Trends in International Mathematics and Science Study (TIMSS), and Progress in International Reading Literacy Study (PIRILS). These large-scale surveys, which were initiated by international organizations such as the Organization for Economic Cooperation and
Development (OECD), herald a new era for the Norwegian education system. The results of the large-scale surveys, and in particular the PISA surveys, gave legitimacy to significant changes in Norwegian education policy in the early 2000s, with subsequent reforms in schools and later in teacher education. The conversion of the Norwegian teacher education to a five-year master's education received decisive impulses from Finland, a country that can show good results in the international PISA surveys $[2,8]$. In the same way as the Finnish model, the new Norwegian five-year teacher education will emphasize a scientific and research-based content, with the aim of developing a new type of professional knowledge, which will provide a new foundation for teachers' teaching practices in schools.

The new five-year teacher education was launched in 2017, and so far, there is limited research on the effects of the new five-year teacher education in Norway. As mentioned, the reform introduces a new scientific and research-based foundation for students' professional practice. A central research focus is related to the question of students' understanding of knowledge in the new teacher education, and whether knowledge is reduced to knowing in students' knowledge practices. Based on Maton's Legitimation Code 
Theory (LCT) [9], this paper will examine the types of knowledge practices that are expressed in students' research and development (R\&D) papers in the new teacher education.

The reform of Norwegian teacher education can be related to changes in society, where international organizations and schemes have gained greater influence on national education policy [2]. Based on international largescale surveys (PISA, TIMSS, and PIRILS), a significant need was identified in the early 2000s to change the Norwegian school, with greater emphasis on skills and knowledge in education. The idea of creating a knowledge school forms a central basis for the expansion of the Norwegian teacher education to a five-year primary school teacher education at master's level. These guidelines are later specified in several public documents (Ministry of Education and Research, 2016a, 2016b, [10]), which emphasize the need to strengthen teachers' research-based competence and professional-oriented knowledge. In the integrated course of study in the new teacher education, it was assumed that the teachers of the future need more specialization and competence to strengthen the knowledge base for the practice of the profession. In the learning outcome descriptions in the regulations for the curriculum for the new teacher education, three factors are highlighted [10] (pp. 2-authors translation). The candidate must have the following criteria:

(i) Specialized insight into a limited subject area (master thesis)

(ii) Broad professional knowledge in other subjects that are part of the education

(iii) In-depth knowledge of relevant research and theory, as well as scientific thinking, research methods, and ethics

These learning outcome descriptions have been interpreted and processed at institutional level and have been included in the institution's curriculum. Generally, it is a purpose that the students through the study will gain insight into scientific theory and research methods and develop competence to carry out an independent $\mathrm{R} \& \mathrm{D}$ - paper and write a master's thesis. The new five-year teacher education was initiated in 2017. As mentioned, there is a limited research on the effects of the new five-year teacher education in Norway. An exception is a small study from the University of Tromsø, which anticipated this development with a pilot project, and was early in starting five-year teacher education in Norway. This study, which deals with science, concluded that the master's program in science has only to a small extent managed to increase learning pressure and academic level in the first three years of the study [11]. The new teacher education emphasizes that students should develop research-based professional knowledge, but a follow-up study from Østfold University College concludes that students have little understanding of what this research-based professional knowledge is about [12]. These studies provide some indications of real problems in the new five-year teacher education, and in this paper, we will investigate what kind of knowledge is expressed in the students' $R \& D$ papers at Nord University, uncover the underlying organizational principles, and look at the further effects for progression and knowledge building.

\section{Method and Data Sources}

The new five-year teacher education should according to the guidelines of the authorities be based on knowledge and research, and students should develop research-based professional knowledge in the education. In the new Norwegian five-year teacher education, the bachelor thesis has been replaced by an $R \& D$ thesis. The $R \& D$ papers should include a teaching subject and the subject area pedagogy and student knowledge. The scope and organization of the thesis is determined by the institutions, and in the study plan for Nord University, this is formulated as follows [13] (curriculum for MAGLU 1-7, 2017, p. 27-authors' translation).

In the third year of study, the student must write a research and development (R\&D) paper in combination between one of the teaching subjects and pedagogy and student knowledge. The papers must be professionally oriented and linked to the field of practice or other aspects of the school's activities. The issue must be linked to key academic, didactic and/or other pedagogical challenges the school faces.

The goal of the $\mathrm{R} \& \mathrm{D}$ papers is to develop a researchbased and profession-oriented form of knowledge. This knowledge should give the student a theoretical basis for practicing the profession. At the same time, the R\&D paper will lay a further foundation for the work on the master's thesis. In the third year of study, students will submit an independent $\mathrm{R} \& \mathrm{D}$ paper, and this project includes submitted R\&D papers in the spring of 2020 at Nord University. This project includes all R\&D papers submitted in Nord University-Nesna, a total of 25 papers $(P 1, P 2, \ldots, P 25)$. This paper will examine the types of knowledge that are expressed in the students' R\&D papers, uncover underlying organizational principles, and look at further effects for progression and knowledge building. Based on the mentioned research questions, a special form of semantic analysis will be used in the project [9]. The R\&D papers are stored in Inspera in Nord University, and after an approved application from Norwegian center for Research Data, an extract of these R\&D papers has been made.

2.1. Theoretical Framework: LCT Semantics. To investigate the types of knowledge practices that characterize students' R\&D papers, this project will be based on Maton's LCT $[4,9]$. This theory builds on Bernstein and Bourdieu, among other approaches [14]. LCT comprises several dimensions or sets of concepts $[4,9]$, and in this project, one concept, semantic gravity, from the dimension named "Semantics" will be used to analyse R\&D papers. Semantic gravity is an approach that can uncover the context-dependency of meanings and is well suited to investigate knowledge practices in the $\mathrm{R} \& \mathrm{D}$ papers and differentiating the forms of 
knowledge that are involved in the practices. Maton [15] (pp. 65-66) defines "semantic gravity" as follows.

The degree to which meaning relates to its context, whether that is social or symbolic. Semantic gravity may be relatively stronger (+) or weaker (-) along a continuum of strengths. The stronger the semantic gravity $(S G+)$, the more closely the meaning is condensed within symbols; the weaker the gravity (SG-), the less dependent meaning is on its context.

Semantic gravity refers to the meaning's dependence on the context. The context dependence of meanings allows an almost infinite grading of strength, where strong semantic gravity (SG+) refers to meanings that largely depend on the context (e.g., about a specific event or experience), while weak semantic gravity refers to more context-dependent meanings (e.g., theoretical explanations of the event). The concept semantic gravity allows to uncover variations of context dependence in meanings and practices by showing that all forms of practice have a different semantic strength.

Semantic gravity provides opportunities to grade practices and to track changes in practices, in the span between weakening semantic gravity and strengthening semantic gravity. Knowledge practices, as expressed in the students' $\mathrm{R} \& \mathrm{D}$ papers, can move from concrete particles in specific cases to more abstract and general concepts, and vice versa to a downward shift to specific contexts and meanings. These movements can be described as the gravity range of practices. Maton [4], (pp.106-124), formulated a term that describes the difference between the strongest and weakest strengths of the practices.

Gravity range is a term that can be related to knowledge building, where a distinction can be made between cumulative knowledge building and segmental knowledge building [16] (p. 108). Cumulative knowledge building provides students with access to conceptual or theoretical knowledge, based on earlier acquired knowledge and allows the integration and expansion of that knowledge across contexts and time. Segmental knowledge building is achieved when knowledge is strongly bound to a context and only meaningful in this context.

Semantic gravity can reveal the context dependence of knowledge, what forms of knowledge that are included, and how they are linked together in the students' R\&D papers. A key goal in the new Norwegian teacher education is for students to develop and apply professional knowledge. Although the term professional knowledge seems to refer to specialized knowledge, neoliberal education reforms, with their emphasis on competence and skills, have created a situation where it is less clear what is meant by this term [17]. As mentioned, professional knowledge is a contentious concept in the new Norwegian teacher education, and there is a need for some criteria that can differentiate between different forms of knowledge in the profession, which allow these concepts of knowledge to be linked to semantic gravity. Professional knowledge is a specialized form of knowledge that includes theoretical and practical knowledge [17], which enables the members of the profession to perform tasks within a particular area. In an analysis of different curricula, based on Maton's model, Shay [18] (p. 572) differentiates between four fundamentally different kinds of knowledge in curriculum: theoretical, practical, generic, and professional. The profession's knowledge is a blended form of specialized knowledge, and Muller argues that this knowledge can be arranged in two different ways in the curriculum, either by being organized on the basis of conceptual or contextually dominant coherence principle [19] (p. 216). This approach helps a bit on the way, but we should emphasize that professional knowledge is a distinct form of knowledge, which includes combinations of context-dependent and more abstract forms of knowledge. To explore this, we need to move beyond types to explore organizing principles, which "semantic gravity" enables us to do. Nevertheless, Muller's coherence principle opens the possibility of different combinations, where the knowledge of the profession can be defined on the basis of different degrees of context dependence. These combinations will have different degrees of semantic gravity strengths, from contextual and local knowledge with a more limited range of semantic gravity, to knowledge that combines practical knowledge with conceptual knowledge, which gives a greater range. It is only this last form of knowledge that gives students epistemic access [20], (p. 140), with opportunities for "conceptual progression" [16], (p. 172), and cumulative knowledge building, with the potential to develop a more general form of knowledge, which can be transferred to new contexts. We will, based on the concept semantic gravity, argue that this is the hallmark of a new scientific and research-based concept of professional knowledge in school and teacher education.

2.2. A Translation Device for Analysing Student Papers. In order to create a connection between theory and data, there is a need to develop what Maton and Chen [21] call a "translation device" that makes visible how theory is realized in the empirical data and provides a bridge between the two. A translation device makes clear to others how concepts are enacted in analysis. Our own translation device has been developed with the aim of creating a connection between the concept of semantic gravity and students' R\&D papers in the new teacher education. As mentioned, all practices include semantic gravity, with varying degrees of semantic strength. These variations in the context dependence and complexity of the sentences produce semantic changes, something Maton [4] refers to as range of semantic gravity.

In this paper, we follow Georgiou's approach [22], where students' ideas, understanding, or conceptions are related to a framework that focuses on objectified knowledge, and where the analysis of students' responses is linked to the concept of semantic gravity, with meanings that may have a stronger or weaker context dependence. Georgiou's study deals with students' responses to a particular problem in physics [23], a subject with a hierarchical knowledge structure [24], where the object is a phenomenon in the natural world. Our translation device follows Georgiou but reflects also that our study has a different context, with a focus on students' R\&D papers, which are implemented 
based on a new, research-based concept of professional knowledge. The translation device is developed in relation to the concept of semantic gravity, where the students' papers are coded based on three levels (see Table 1).

Based on the concept of semantic gravity, it is possible to identify which forms of knowledge practices that are expressed in the students' R\&D papers. Table 1 has a design that provides opportunities for a semantic analysis of students' understanding of knowledge, expressed by the knowledge practices that are expressed in students' $R \& D$ papers. This approach has a focus on students' ideas or conceptions [25]. Following Georgiou [22], the term "conceptions" is understood as a term that gives name to students' understanding of knowledge units, where the composition and connection between the knowledge units or levels will represent a complete or incomplete understanding of scientific and research-based knowledge [26, 27]. Based on Table 1, the last condition is expressed, when the students' practices in the papers create connections between the three different semantic levels. In the new and reformed Norwegian teacher education, where students' instructions and training take place in the span between knowing and knowledge, the three-part division, and the examination of the connections between the three levels, provide an opportunity to uncover the semantic strength and SG range of students' knowledge practices in the submitted R\&D papers. This approach presupposes a special form of semantic analysis, where the paper's constellations of meanings on one level are seen in the context of the paper's structure and content on another level, by examining whether there are connections between the different levels, to determine the paper's range of semantic gravity. This study of connections includes analyses of whether there is a connection between theories, sources, and data and assessments. Of particular importance is the question of how sources and data, directly or indirectly, are explained in the papers. The content of the student's explanations, whether they are related to the theories and concepts, or have a more local and contextual character, is included as a central analysis point, which provides an opportunity to map different forms of knowledge, and the organizational principles behind this knowledge, in the students' R\&D papers in this study.

\section{Results}

The analysis of the students' R\&D papers was carried out based on a translation device (see Table 1), which indicates three levels, suitable for uncovering the range of semantic gravity in the students' papers. The semantic analysis focused on content and structure and whether the practices create connections between the different levels, or whether these connections are missing.

Figure 1 gives an overall visual representation of the forms of SG range that are expressed, in the span between SG- and SG+, in the students' papers.

The papers with greater SG range (B1, Figure 1) include connections between all three levels: theories and concepts (SG-) are related to sources and data (SGØ), and connections to theories and concepts are maintained and applied in the student's own assessments of the data in the thesis (SG-, SG+). Typical of papers in this category is that data is explained with terms derived from theories. For example, in a paper $(P 4, \mathrm{~B} 1)$, the student examines the connection between fiction books and self-image and draws the following conclusion: "Fiction about the difficult topics can make a positive contribution to the development of children's selfimage, but there are many factors that will influence this." In the paper, the student discusses these factors based on literary theory and pedagogical theories.

The papers with a more limited SG range (A2, Figure 1) have in common that they are missing connections to theories and concepts, either because the paper lacks a prepared theoretical basis, or because theories and concepts are not used in the student's own assessments, or where references is made to public documents and selected literature references, which means that the student's assessments of data are based on simpler and more context-dependent meanings. Typical of these papers is that explanations of data, often with elements of carefully selected literature quotations, are handled in a reflexive and constructivist way. For example, in a paper $(P 9, \mathrm{~A} 2)$, which examines whether conversation-based teaching can strengthen students' reading skills in the subject Norwegian, the student discusses opportunities and challenges with such a working method. The student concludes, based on a selection of literature references, that "the good conversation can help to strengthen students' mastery experiences, either by making the students aware of their mastery or by making the teacher aware of what the students experience that they do not master." In this way, papers in this category create a connection between two levels, between the student's assessments (SG-, SG+) and sources and data (SGØ), which gives these papers a context-specific and segmental character.

The analysis shows that the range of semantic gravity in the student papers varies considerably and covers from two (A2) and three levels (B1), respectively. These differences in SG range, where students connect different levels, reveal the underlying organizational principles of the different papers, expressed by the relative strength of semantic gravity ( $\mathrm{SG} \pm$ ). The different degree of semantic strength provides opportunities to determine the types of knowledge that characterize students' $\mathrm{R} \& \mathrm{D}$ papers.

The semantic analysis shows that the students' $R \& D$ papers are characterized by a connection between different levels, which have different SG range.

Figure 2 shows that a little more than half of the submitted student papers have a greater SG range (52\%). These papers are based on a form of knowledge, which includes three levels, where there are connections between theory and concepts, sources and data, and the students' assessment of this data in papers. Although these papers are quite different, all papers have a theoretical basis, which means that these papers combine the contextual with more general theoretical knowledge, which is less dependent on the context. It is precisely this combination that characterizes a scientific and research-based concept of professional knowledge. This form of knowledge provides students with a theoretical basis for practicing the profession, which is a prerequisite for "the 
TABLE 1: A translation device for semantic gravity.

\begin{tabular}{|c|c|c|}
\hline $\begin{array}{l}\text { Semantic } \\
\text { gravity }\end{array}$ & $\begin{array}{l}\text { Coding } \\
\text { categories }\end{array}$ & Description of coded content \\
\hline Weaker & SG- & $\begin{array}{l}\text { The student describes theories, concepts, or principles in a general manner, without reference to a } \\
\text { specific situation or social conditions }\end{array}$ \\
\hline Medium & SGØ & $\begin{array}{l}\text { The student describes the object(s), by referring to various sources, facts or data, and providing some } \\
\text { explanations or interpretations (linking SG } \varnothing \text { with SG- and SG+ levels) }\end{array}$ \\
\hline Stronger & SG+ & $\begin{array}{l}\text { The student describes the object(s) or its characteristics, by referring to own experiences, meanings, or } \\
\text { perceptions of a specific situation or social conditions }\end{array}$ \\
\hline
\end{tabular}

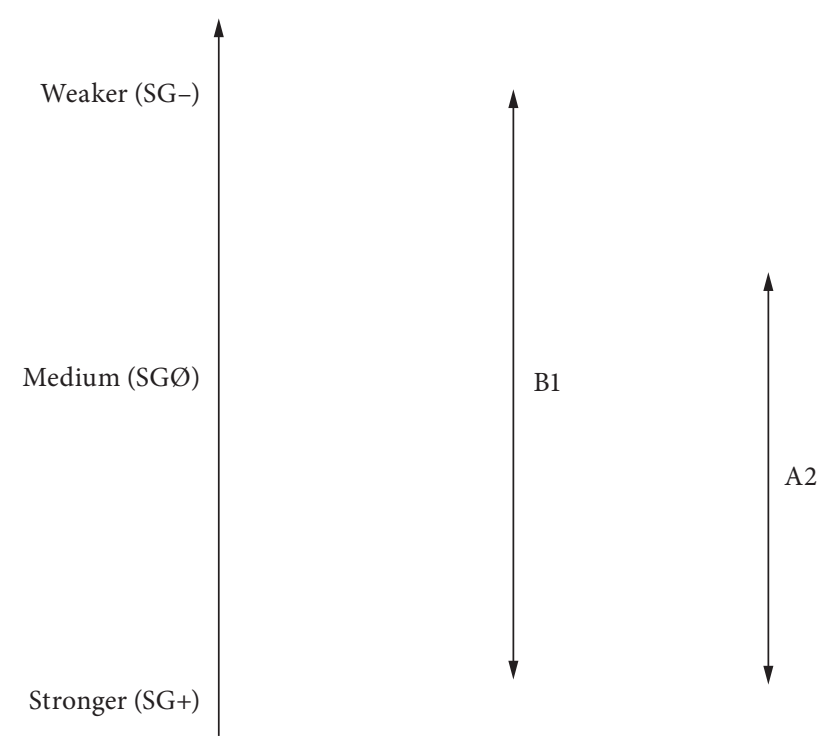

Figure 1: Different semantic gravity ranges in student papers. Shows two different forms of SG range in the students' R\&D papers, referred to as papers with a long SG range (B1-covers three levels) and papers with a more limited SG range (A2-covers two levels).

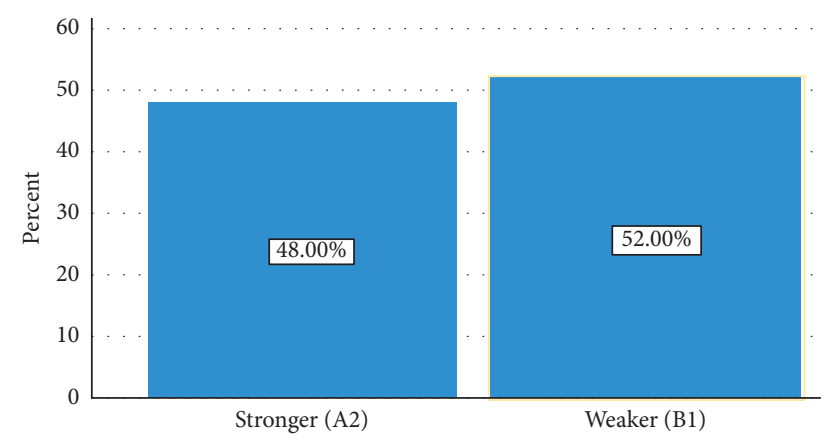

FIGURE 2: Relative strengths of semantic gravity in student papers.

confident embedding of theoretically informed action in practice" [28].

On the other hand, slightly less than half (48\%) of the analysed papers are characterized by a more limited SG range, which indicates that many students have not acquired a clear understanding of what is meant by professional knowledge in the new Norwegian teacher education. Figure 2 shows that many of the students' R\&D papers are characterized by a more context-dependent form of knowledge. R\&D papers in this category are characterized by a connection between two levels, between sources and data, and the students' own assessments of data in the assignments. In these papers, the teachers' knowledge base is understood as a context-dependent form of knowledge, which is not connected to concepts and theories. This form of knowledge is based on the idea that knowledge is something local, which can be explored through research related to specific practical problems, and which can be developed to a higher level by drawing on selected literature references and authoritative sources, something which can lead to a more developed understanding of the problems presented, often by finding specific interpretations of sources or data.

\section{Discussion}

The reform in the new Norwegian teacher education aims to develop a new type of professional knowledge, based on science and research, which will strengthen the basis for teachers' teaching practices in schools [12]. The question of what we can understand with teachers' professional knowledge is a controversial topic in the Norwegian teacher education. In this section, we will discuss the concept of professional knowledge considering the result of the semantic analysis of the students' R\&D papers and consider further effects on possibility for progression and knowledge building.

The result of the LCT analysis shows that the students' $\mathrm{R} \& \mathrm{D}$ papers have different strengths (Figure 2) of semantic gravity. Papers in the category with stronger semantic gravity comprise two levels (48\%) and are characterized by a limited SG range. Papers in this category highlight that the teacher's professional knowledge is a practical form of knowledge, a kind of know-how specialization, with mastery of teaching methods and techniques to promote learning and motivate students in school. This specialization, which is often based on specific problems in school, may include references to subject literature and public documents, but is still characterized by a context-dependent form of knowledge. This knowledge is developed and specialized based on a contextual purpose and dominated by what Muller [19] has described as contextual coherence. Although this form of knowledge opens for contextual specialization, with development and innovation, papers in this category are characterized by a limited SG range, with little degree of renewal of established practices. Norwegian schools and teacher education have for a long time been characterized by a particularly Scandinavian version of progressive pedagogy 
[2], and in several papers in this category, practices with student-active working methods are emphasized as the solution to problems with learning in school, a solution that is put forward without considering the specialized knowledge the pupils should learn in the subject.

Student papers with a longer SG range include three levels (52\%), where there is a connection between theories and concepts, sources, and data, and where students interpret and explain data in the light of theory. Studies of contextual practices, as expressed in students' data, are informed by theories and concepts. The semantic structure, which connects the three levels, includes various forms of knowledge, where contextual practices in the classroom are understood and developed based on the concepts that are used. This version of the teacher's professional knowledge is based on a conceptual coherence principle [19]. This principle of coherence connects the various forms of knowledge and opens for a double specialization [17], with the development of context-specific practices in the classroom based on concepts, with opportunities for concept development towards an increasing degree of conceptual integration and conceptual generality [16]. Student papers in this category are particularly marked by the development of contextual knowledge considering the concepts that apply. However, the specialized development of the contextual practices takes different paths, where a distinction can be made between the use of recontextualized pedagogical concepts and concepts taken from the subject area, which shows that students have a quite different understanding of what we can understand with the teacher's professional knowledge in school.

The analysed R\&D papers give a complex picture and show that there are large differences in what the students in the new Norwegian teacher education understand by the concept of professional knowledge. Papers with limited semantic reach are characterized by local and context-related forms of knowledge, without connection to theories and concepts, with practices that provide segmental forms of knowledge building. For teachers and students, such a context-dependent form of knowledge represents few opportunities for development. Student papers with a longer SG range combine studies of contextual practices with concepts and theory, which opens for cumulative forms of knowledge building. When data is linked to theories and concepts, with practices that condense abstract and variable meanings, a form of complex conceptual knowledge is developed, which can lift the knowledge out of the given context, with relevance to other and new contexts [4]. Papers with a greater SG range offer a lesson in how research-based knowledge can provide a new basis for teachers' professional practices in education. The concept of semantic gravity reveals the papers' semantic structure and demonstrates that scientific and research-based professional knowledge is a context-transcendent form of knowledge. It is a knowledge that can lead to the development of new knowledge, with capacity for cumulative knowledge building, where students' acquired knowledge which can be transferred to new contexts in time and space. At the same time, these students' papers raise new questions about the relationship between practice and theory, how concepts can shape and develop practices in the classroom, and what kind of concepts and theories that can best contribute to cumulative knowledge building in school and teacher education.

\section{Conclusions}

This paper starts with the reform of the Norwegian teacher education, a reform that expands the teacher education to a five-year master's education. A key purpose of the reform is to strengthen the knowledge base for teachers' professional practice, by introducing a scientific and research-based concept of professional knowledge. This approach heralds a shift, with the expectation of a development away from a one-dimensional focus on context-dependent practices, characterized by a "subjective doxa" [4], where learning and knowledge are understood as ways of knowing. This paper examines the types of knowledge that are expressed in the students' R\&D papers in the new teacher education. The results of the study reveal that there is a gap between the intentions and realities of the reform, expressed in the forms of knowledge that are expressed in the students' papers. Almost half of the R\&D papers are marked by a more context-dependent form of knowledge, with a limited range of semantic gravity, which suggests that many students do not have a clear understanding of what is meant by scientific and research-based professional knowledge. This result, where there is a gap between the intentions and realities, reveals a condition which can be referred to as "code clash" [29]. The analysis shows that these papers are characterized by a more context-dependent form of knowledge, characterized by contextual coherence [19]. This form of knowledge has effects, where the students' form of knowledge building acquires a local and segmental character, and where this knowledge is difficult to transfer to new contexts. When knowledge is extracted from practice and principles, without connection to theories, the knowledge will be dependent on the given context, something that locks students into a more traditional understanding of the practices of the profession. This indicates that the progressive pedagogy, with a doxa where knowledge is reduced to ways of knowing, still holds a relatively strong position in the Norwegian teacher education. The strong position of the progressive pedagogy has effects on students' perceptions of learning and knowledge. In what way the progressive pedagogy manifests itself and how it shapes the students' perception of knowledge in the Norwegian teacher education are questions open to further research.

\section{Data Availability}

This project includes all R\&D papers submitted in in the Spring of 2020 at Nord University, Nesna-a total of 25 papers. This paper examines the types of knowledge that are expressed in the students' $R \& D$ papers. The $R \& D$ papers are stored in Inspera in Nord University, and after an approved application from Norwegian Center for Research Data (NSD), an extract of these R\&D papers has been made. 


\section{Conflicts of Interest}

The authors declare that there are no conflicts of interest regarding the publication of this paper.

\section{References}

[1] E. Bratland, "Technology and education: why do students still need access to specialized knowledge?," in ICT in educational design, E. Baron-Polańczyk, Ed., vol. 12, pp. 37-49, Zialona Gora University Press, Zielona Gora, Poland, 2018.

[2] E. Elstad, Lorerutdanning I Nordiske Land, Universitetsforlaget, Oslo, Norway, 2020.

[3] R. K. Sawyer, The Cambridge Handbook of the Learning Sciences, Cambridge University Press, Cambridge, UK, 2006.

[4] K. Maton, Knowledge and Knowers: Towards a Realist Sociology of Education, Routledge, Abingdon, UK, 2014.

[5] E. V. Glasersfeld, Radical Constructivism: A Way of Knowing and Learning, Falmer Press, Falmer, UK, 1995.

[6] U. Blossing, G. Imsen, and L. Moos, "Progressive education and new governance in Denmark, Norway, and Sweden," in The Nordic Education Model: "A School for All" Encounters Neo-Liberal Policy, U. Blossing, G. Imsen, and L. Moos, Eds., Springer Netherlands, Dordrecht, Netherlands, pp. 133-154, 2014.

[7] G. Imsen and M. R. Ramberg, "Fra progressivisme til tradisjonalisme i den norske grunnskolen?" Sosiologi $i$ dag, vol. 44, no. 4, pp. 10-35, 2014.

[8] S. Østerud, "Hva kan norsk skole lære av PISA-vinneren Finland?" Nordisk Tidsskrift for Pedagogikk Og Kritikk, vol. 2, pp. 14-35, 2016.

[9] K. Maton, S. Hood, and S. Shay, Knowledge-Building: Educational Studies in Legitimation Code Theory, Taylor \& Francis Group, Abingdon, UK, 2016.

[10] Kunnskapsdepartementet, "Forskrift om rammeplan for grunnskolelærerutdanning for 5-10 trinn," Norsk lovtidend, Avd. I, 2016.

[11] S. Karlsen, M. Olufsen, O. A. Haugland, and S. Thorvaldsen, "Et tidlig gløtt inn i den nye norske lærerutdanningen: En komparativ studie av allmennlærer-og masterutdanning i naturfag for grunnskolen," Uniped, vol. 40, no. 4, pp. 299-311, 2017.

[12] H. Afdal and F. R. Bjordal, 5-årig Grunnskoleloererutdanning P̊̊ Masternivå-Ny Og Utfordrende: Et Følgeforskningsprosjekt Ved Høgskolen I Østfold: Delrapport I, Universitetet i SørøstNorge, Notodden, Norway, 2019.

[13] Nord universitet, "Studieplan. Grunnskolelærerutdanning 1-7. trinn-5-årig master," 2017.

[14] K. Maton and R. Moore, Social Realism, Knowledge and the Sociology of Education: Coalitions of the Mind, Continuum, Houston, TX, USA, 2010.

[15] K. Maton, "Theories and things: the semantics of disiplinarity," in Disciplinarity, F. Christie and K. Maton, Eds., pp. 62-84, Continuum International Publishing, London, UK, 2011.

[16] E. Rata, "A pedagogy of conceptual progression and the case for academic knowledge," British Educational Research Journal, vol. 42, no. 1, pp. 168-184, 2016.

[17] M. Young and J. Muller, "Towards the sociology of professional knowledge," in Knowledge, Expertise and the Professions, M. Young and J. Muller, Eds., pp. 3-17, Routledge, Abingdon, UK, 1 edition, 2014.

[18] S. Shay, "Conceptualizing curriculum differentiation in higher education: a sociology of knowledge point of view," British
Journal of Sociology of Education, vol. 34, no. 4, pp. 563-582, 2013.

[19] J. Muller, "Forms of knowledge and curriculum coherence," Journal of Education and Work, vol. 22, no. 3, pp. 205-226, 2009.

[20] S. Shay, "Curriculum in higher education: beyond false choices," in Thinking About Higher Education, P. Gibbs and R. Barnett, Eds., pp. 139-155, Springer, Berlin, Germany, 1st edition, 2014.

[21] K. Maton and R. Chen, "LCT in qualitative research: creating a translation device for studying constructivist pedagogy," in Knowldege-Building. Educational Studies in Legitmation Code Theory, K. Maton, S. Hood, and S. Shay, Eds., pp. 45-66, Routledge, Abingdon, UK, 2016.

[22] H. Georgiou, "Putting physics knowledge in the hot seat: the semantics of student understandings of thermodynamics,", in Knowledge-Building. Educational Studies in Legitmation Code Theory, K. Maton, S. Hood, and S. Shay, Eds., pp. 194-210, Routledge, Abingdon, UK, 2016.

[23] H. Georgiou, K. Maton, and M. Sharma, "Recovering knowledge for science education research: exploring the "icarus effect" in student work," Canadian Journal of Science, Mathematics and Technology Education, vol. 14, no. 3, pp. 252-268, 2014.

[24] B. Bernstein, Pedagogy, Symbolic Control and Identity: Theory, Research, Critique, Rowman \& Littlefield, Lanham, MD, USA, 2000.

[25] Y.-H. Chang, C.-Y. Chang, and Y.-H. Tseng, "Trends of science education research: an automatic content analysis," Journal of Science Education and Technology, vol. 19, no. 4, pp. 315-331, 2010.

[26] X. Liu, "Synthesizing research on student conceptions in science," International Journal of Science Education, vol. 23, no. 1, pp. 55-81, 2001.

[27] S. Vosniadou, International Handbook of Research on Conceptual Change, Routledge, Abingdon, UK, Second edition, 2013.

[28] L. Clarke and C. Winch, "Apprenticeship and applied theoretical knowledge," Educational Philosophy and Theory, vol. 36, no. 5, pp. 509-521, 2004.

[29] S. Howard and K. Maton, "Theorising knowledge practices: a missing piece of the educational. technology puzzle," Research in Learning Technology, vol. 19, no. 3, pp. 191-206, 2011. 